\title{
Filosofia cínica contemporânea e dispositivos éticos de resistência em Mula de Deus, de Hilda Hilst
}

\author{
Jorge Alves Santana ${ }^{1}$
}

\begin{abstract}
Escrituras de pena (diria mais, de pelos)
De infinita tristura, encerrada em si mesma

Quem há de ouvir umas canções de mula?
\end{abstract}

Hilda Hilst

Para que a cidade possa existir, para que possa ser salva, ela precisa de verdade. Mas a verdade não pode ser dita num campo político definido pela indiferença entre os sujeitos falantes.

Michel Foucault

Há, de fato, algo que o homem é e tem de ser, mas este algo não é uma essência, não é propriamente uma coisa: é o simples fato da sua própria existência como possibilidade ou potência. Mas é justamente por isso que tudo se complica, que a ética se torna efetiva.

Giorgio Agamben

\section{Introdução}

Estar sendo: ter sido (1997) é a última narrativa publicada em vida de Hilda Hilst. O que talvez possa coroar uma vasta produção literária que abrange vários gêneros textuais usados para a engenharia de um dos mais instigantes e intrigantes projetos estéticos da literatura brasileira contemporânea. Particularmente nessa obra, acompanharemos a fase final da vida do protagonista Vittorio, escritor de roteiros cinematográficos, que se isola em uma pequena vila, ao lado de familiares e alguns conhecidos, para vivenciar intensamente a instalação da velhice em sua vida e a indefectível preparação para a morte que lhe aponta pragmaticamente no horizonte.

1 Doutor em estudos literários e professor da Universidade Federal de Goiás. E-mail: jorgeufg@bol.com.br 
Nesse quadro de finitude humana, temos que tal narrativa explorará estratégias de negociações e de enfrentamentos ao contexto psicossocial adverso, usando, por exemplo, valores e procedimentos vinculados ao campo da parresía cínica ${ }^{2}$ em diálogo com alguns valores da ecocrítica (pensamento ecológico vinculado à estética). Esse dispositivo discursivo literário será, pois, envolvido por outras estratégias discursivas de pensamentos, valores e crenças expressos de modo franco, direto e ousado no sentido de se tentar deslocar o que seriam certas verdades tradicionais. Tais estratégias são movidas pelas necessidades de se desconstruir conceitos e preconceitos que obstaculizam a vontade de vida do protagonista em questão. Tal vontade é sistematizada, entre outros, por Arthur Schopenhauer (2002), no que concerne à ontogênese do campo do desejo, com suas sensações e afetos, em confluência com o campo da realidade, construído por sobredeterminações pessoais, interpessoais e institucionais.

Esse protagonista, disposto por um narrador que lhe é empático, é envolvido por diretrizes montadas pelo pensamento ecológico - o mental, o social e ambiental - que tentará modificar o corolário que envolve a dimensão de sua velhice. Essa fase, tida como fonte de sofrimentos psicofísicos, será transposta para uma dimensão da razão prática, questionadora das acomodações advindas de possíveis consolações garantidas por metafísicas convencionais, como as religiosas.

De textualização heterogênea quanto a perspectivas de gêneros literários, a narrativa predominantemente expressa em prosa, será hibridizada pela presença marcante de fragmentos de poemas e de poemas completos. Observaremos particularmente o poema que encerra essa narrativa, intitulado Mula de Deus, no que ele possui de síntese das ideias poetizadas tanto nessa narrativa quanto em outras narrativas da escritora, com as quais essa última obra se intertextualiza de modo explícito.

Esse poema final, que parece funcionar como um balanço políticofilosófico tanto do eu ficcional quanto do eu factual, também nos aproxima dos meandros de certas percepções do paradigma estético da escritora. Dessa forma, ao lado das estratégias discursivas utilizadas, também refletiremos sobre possíveis biografemas (Barthes, 1994), presentes

\footnotetext{
${ }^{2}$ Aqui, o conceito de parresía é aquele dos últimos cursos ministrados por Michel Foucault (2011; 2010), no Collège de France, que tratam dos cuidados de si, dos outros e do socius, predominantemente na ambiência do mundo grego antigo e, por consequência, também da época contemporânea.
} 
tanto no poema indicado, quanto na organicidade dessa narrativa, que nos apontam ações e situações impulsionadas pela parresía cínica, percebida como discurso propedêutico e judicativo, de caráter franco e pragmático quanto a valores e crenças de uma coletividade na qual o dispositivo da verdade deve/pode ser questionado de modo constante por princípios éticos democráticos.

Tal estratégia socioestética da parresía será também percebida na dimensão da perspectiva cínica, postura semelhante àquela da antiguidade clássica, capaz de desconstruir universos existenciais disfuncionais, de modo irônico, disfêmico, grotesco e risível, para as tentativas de possível reordenação de tais universos. Essas reordenações supõem a presença de sujeitos que atuem como agentes sociais ativos nos fenômenos de coexistência humana e ecológica.

O poema Mula de Deus, será aqui então perspectivado pela noção de que o ser humano, frente à velhice e à morte psicossocial, e até mesmo física, também possui a capacidade de posicionar-se de modo cínico/crítico, com a esperança talvez de minimizar a dependência de supostas consolações metafísicas, exigindo respostas éticas de sua rede de convivência para que sua dignidade humana seja assegurada. Essa posição de risco pessoal e de tensão perante posições conservadoras da coletividade que se enfrenta, desenha aquela cartografia na qual podemos perceber o valor positivo que se dá ao campo de influência e de sobredeterminação dialéticas do que se considera por razões práticas, aquelas mais do campo das imanências que das transcendências.

Três frentes, pois, performam nossa proposta de estudo: uma narrativa literária que expressa subjetivações em curso no campo do envelhecimento e da velhice perante a finitude, demonstrando de forma vigorosa, franca e cínica as condições do lugar psicossocial negativizado que lhe é imposto. Uma segunda frente, em refletirmos sobre as formas de resistência, de discussão sobre posturas éticas; dimensão percebida quando acompanhamos o protagonista dessa narrativa de Hilda Hilst negociando estratégias da ecocrítica, entre outras, que intentam resgatar a natureza que existe em si, como mecanismo protetivo dos abusos e da condição vulnerável que os espaços urbanos/civilizados lhe impõem. A terceira frente fecha este estudo hipostasiando as formas híbridas da linguagem literária que expressa essa condição complexa do protagonista subjetivando-se 
provisoriamente em contextos francamente adversos que lhe exigem posturas de resistência, através da razão predominantemente prática (Bourdieu, 1996), via ações pontuais nas cobranças cínicas de comportamentos humanos, no plano da justiça isonômica, que perfazem seu socius.

\section{Dispositivos da filosofia cínica na presença da velhice e da morte}

Estar sendo: ter sido, como já apresentamos, traz o escritor de roteiros cinematográficos Vittorio. Tal personagem está instalada na velhice oficial (a tal fase dos 60 anos ou mais) e deixa um grande centro urbano para viver o que considera ser seu último tempo, em uma pequena comunidade interiorana. É, pois, mais uma personagem diaspórica do conjunto de personagens comuns a outras obras de Hilda Hilst. Isso, naquele sentido de inserção psicossocial em contextos experienciais de inovações de vida tanto pessoal quanto coletiva.

Vittorio debruça-se sobre sua condição de velhice instalada e a experimenta de modo visceral. Seu corpo envelhecido, formado por vários vetores de subjetivação e pelas inevitáveis e inusitadas particularidades fisiológicas, não mais lhe obedece como outrora. Sente e se ressente dos dentes que se enfraquecem e caem, que seus cabelos embranquecem, raleiam e somem, que as pernas the tremem, que seu órgão sexual parece inativo, que sua autonomia e independência acionais tomam formas desconhecidas, que seu raciocínio não produz de modo tão eficiente o trabalho pelo qual conseguiu sustentar a si mesmo e a sua família, construindo sua identidade profissional e criativa.

Nesse contexto, observamos como suas insatisfações e medos vão aumentando gradativamente, no curso de sua narrativa feita pela potente intersecção entre subjetivação do enunciado e subjetivação da enunciação, até que se alcance o clímax de desespero e de inação semelhante ao da morte física. No caso da narrativa hilstiana, o fenômeno da morte/finitude é representado frequentemente mais por uma ambiência semântica plurissignificativa que por uma referencialidade exata, mesmo que a finitude física seja realmente pontuada. Vejamos como o jovem velho senhor percebe-se a si mesmo nessa fase: 
Ando mal das pernas. Júnior e Matias dizem que penso que não posso andar. Comprei uma linda bengala, a cabeça de um tigre de prata na ponta, puxa-se a cabeça e sai uma linda espada, comprei muletas de mogno, e uma cadeira de rodas que não só vai pra frente e para trás, mas rodopia, para com precisão sem te lançar pra fora, e se alguma coisa emperra, toca uma musiqueta, uma espécie de minueto... a mesma fábrica que faz a cadeira deve fazer caixinhas de música e naturalmente tem a mesma coisa para as duas coisas. Algumas manhãs acordo muito mal, as pernas bambeiam muito, fico parado tremelicando, aí dou aquele grito MATIAS, e ele vem com o álcool e cânfora dentro da garrafa e me esfrega vigorosamente as pernas. Matias é um santo, só não suporto as amantes dele (Hilst, 2006, p. 123-124).

Um notório e quase estereotipado quadro da velhice - destituída de autonomia e de independência em relação à sua gerência pessoal e interpessoal - vai se consolidando e é detalhadamente expresso pela própria voz enunciativa de quem sente tal fase da vida em seu próprio corpo. A voz da pessoa envelhecida é dada, pois, junto a uma disposição enunciativa repleta de desejos, apesar de movimentos erráticos, de compreender como tal quadro vivencial é disposto na coexistência com várias outras personagens de seu entorno.

Basicamente dividida em duas partes, a narrativa de Estar sendo: ter sido, termina tais partes com uma rizomática estrutura genológica, no sentido de variadas possibilidades de modalidades textuais usadas. Se há certa ênfase na narrativa prosaica, mesmo que com intensos traços de asignificação, após o ápice do grande surto comportamental do protagonista, que praticamente entra em colapso psicofísico, e do ápice da segunda parte, que seria a presença de uma suposta abnegação perante o irremediável da morte, vemos que a linguagem poética, em forma de poema, domina a atmosfera dessa textualização literária.

Tal narrativa é terminada/coroada pelo longo poema Mula de Deus, de cunho alegórico e ao mesmo tempo repleto de elementos da razão prática, sobretudo a ecológica, que nos leva a pensar sobre nossas relações com os fenômenos do envelhecimento, da velhice instalada e, sobretudo, da morte em nossas realidades cotidianas. Além disso, a morte aí também pode ser percebida sendo influenciada por traços de misticismo crítico e natural, montado por um denso devir-animal do protagonista/eu-lírico na forma animalesca de uma mula. Um animal prosaico/vulgar, que se 
coloca diante das forças imponderáveis, como que assumindo sua condição de falência humana após uma existência pessoal heterogênea e confusa, mas cuja existência parece ter gerado frutos sólidos para se reestruturar sua condição pessoal e interpessoal que lhe gerara situações adversas.

Mula de Deus, poema que finaliza a narrativa prosaica central, é composto por oito estrofes com número irregulares de versos, bem como é de metrificação variada. Seu fim é marcado por sintagmas aparentemente soltos, expressos em letras maiúsculas. Por fim, há uma epígrafe de James Ward e a data de sua escrita, na Casa do Sol, em 6 de março de 1993, 15 de janeiro de 1996, no período da Lua Nova.

Um de seus núcleos temáticos trata do diálogo/monólogo entre um eu lírico zoomorfizado, no devir animal de uma mula, com uma proteiforme constituição dialógica e agônica conformada por uma figura relativamente divinizada. Uma linha de força do poema é esse diálogo/monólogo que procura tratar da construção, da desconstrução e da suposta reconstrução da vida de tal subjetividade lírica, que traz seus anseios por compreender sua própria condição humana, seu final de vida em atmosfera de desejos frustrados, suas relações afetivas com a família, sobretudo com seu pai, e os encontros e desencontros vivenciais com as várias pessoas que compõem em coautoria sua subjetividade múltipla. Vejamos seu início:

\section{MULA DE DEUS \\ I \\ Para fazer sorrir O MAIS FORMOSO \\ Alta, dourada, me pensei. \\ Não esta pardacim, o pelo fosco. \\ Pois há de rir-se de mim O PRECISO}

Para fazer sorrir O MAIS FORMOSO

Lavei com a língua os cascos

E as feridas. Sanguinolenta e viva

Esta do dorso

A cada dia se abre carmesim.

Se me vires, SENHOR, perdoa ainda

É raro, em sendo mula, ter a chaga

E ao mesmo tempo

Aparência de limpa partitura

E perfume e frescor de terra arada. 
II

Há nojosos olhares sobre mim

Um rei que passa

E cidadãos do reino, príncipes do efêmero.

Agora é só de dor o flanco trêmulo

Há nojosos olhares. Rústicos senhores.

Açoites, fardos, vozes, alvoroço.

E há de mim um sentir delicioso.

Um tempo onde fui ave, um outro

Onde fui tenra e haste.

Há alguém que foi luz e escureceu

E dementado foi humano e cálido.

Há alguém que foi pai. E era meu (Hilst, 2006, p. 123-124).

O diálogo/monólogo, em um primeiro momento, parece construir um exercício de autocompreensão do sujeito para a preparação de sua própria morte. Isso nos ocorre quando nos aproximamos de tal poema, inserindo-o no contexto orgânico da narrativa maior, que é a do escritor Vittorio. Um balanço de vida parece seguir seu curso nos questionamentos que o demasiadamente humano faz perante forças que surgem de seu próprio ser e de forças que aparecem de dimensões metafísicas institucionalizadas de modo tradicional e, portanto, arbitrário. Condicionamos aqui tal dimensão além da coisa física, no sentido de que uma das hipóteses desse nosso estudo é a de que tais forças sobredeterminantes de certo fracasso existencial do protagonista, e do eu lírico poemático, possam ser oriundas de suas realidades concretas, construídas historicamente no embate de ideologias psicossociais heterogêneas e de princípios éticos excludentes. Essa tensão entre conjuntos de valores heterogêneos pode ser percebida na sequência do poema, quando a subjetividade lírica se questiona:

III

Escrituras de pena (diria mais, de pelos)

De infinita tristura, encerrada em si mesma.

Quem há de ouvir umas canções de mula?

Até das pedras lhes ouço a desventura.

Até dos porcos lhes ouço o cantochão

E por que não de ti, poeta-mula? (Hilst, 2006, p. 123-124). 
A subjetividade envelhecida que faz o balanço de sua vida, em suposta preparação para a morte, divide-se entre a vida que talvez desejara, no campo da necessidade de seu fluxo desejoso liberto, e a vida que lhe fora possível, através dos comportamentos possibilitados pela moral hegemônica. Necessidade libidinosa e comportamentos contingenciados pelos dispositivos de existência social conservadora formam, pois, o quadro de aparatos de coerção que lhe obriga a dar satisfações a si mesmo sobre os caminhos que lhe foram frustrados. Pois é de certa frustração existencial que também é feito um dos veios preponderantes desse poema.

O diálogo/monólogo é aberto com uma entidade proteiforme, que realmente é colocada em nível hierárquico superior. Tanto que os vocábulos são colocados no destaque retórico das maiúsculas, como: $\mathrm{O}$ PRECISO, O MAIS FORMOSO, SENHOR. Em primeiro plano, tal interlocutor poderia ser vinculado à deidade, por exemplo, da religião cristã, uma das matrizes religiosas das mais intensas que baseiam várias formações discursivas das obras de Hilda Hilst. A tal entidade, o poema parece dirigir seu questionador balanço de vida, bem como seu acerto de contas, colocando a subjetivação lírica, demasiadamente humana, em patamar de aparente humilíssima condição existencial - que menor que a humana, seria a condição mais miserável que é a da mula velha e em frangalhos físicos na sua velhice.

Nesse ponto de nossa reflexão, percebemos que a voz da contrição está hibridizada pela voz da indagação ativa e autocrítica. Se, no ato da contrição, um dos exercícios básicos para o autoconhecimento que o sujeito pode fazer, acompanhamos o processo de diminuição que o ser faz de si mesmo perante algum princípio ético que porventura tenha descumprido, também percebemos que há uma tendência dessa voz retrospectiva a se colocar no lugar do ser que ousa questionar a existência de tais princípios éticos de produção, contenção, vigilância e controle das condições impostas.

O eu lírico questiona a divindade sobre as razões de sua condição, demonstrando certo comportamento herético diante dos protocolos que tais contextos exigem. A figura divina é inquirida na produção de seus desígnios que dizem respeito à vida humana e, em particular, à vida dessa subjetividade que se contorce no que seriam seus últimos momentos de vida. Naturalmente ou convencionalmente, a mula envelhecida e carcomida pelos remorsos de suas ações passadas deveria 
saber morrer em silêncio, respeitando as diretrizes éticas e morais que lhe foram impostas pelo que seria aquela força metafísica superior. No entanto, sua postura parece não estar aparelhada aos mecanismos das tradicionais consolações oriundas das metafísicas oficiais.

Por caminhos enviesados e estratégicos, a tal mula como que exige ser ouvida em suas dúvidas existenciais: "Escrituras de pena (diria mais, de pelos) / De infinita tristura, encerrada em si mesma. / Quem há de ouvir umas canções de mula?" (Hilst, 2006, p. 123). O discurso contestatório, e também denegador, mostra-se através de sua diminuição cênica perante a entidade que, naturalmente, deveria ser fonte de compreensão, tolerância e empatia para com suas próprias criaturas em situação inferior. Assim, tal diminuição acaba por lembrar à divindade o que seria sua responsabilidade ontológica e ecológica perante a exigência que lhe é feita: a de ouvir os questionamentos sobre as razões de uma vida humana, ou de qualquer outro ser vivo, não ter seguido livremente e positivamente o curso de seus desejos.

Corajosamente esse eu lírico, reflexo e expressão parcial do protagonista Vittorio e biografema da escritora Hilda Hilst, questiona o criador, percebido em sua dimensão proteiforme, pois nele também está implicada a figura de um humano pai falecido, que vemos pelos dados históricos do pai da escritora; nele está a autoridade convencional da mãe ausente, também indiciada pelo biografema da mãe da escritora; nele está a ideologia conservadora da pequena comunidade na qual o protagonista da narrativa central está imerso. Ou seja, a deidade que entra no circuito comunicacional disposto no poema é uma realidade plural que, por fim, parece insistir em determinar certa ordem convencional que alicerça os possíveis estados, condições e ações que determinaram tanto o fracasso do protagonista Vittorio, quanto do eu lírico do poema Mula de Deus.

Que ousadia insufla essa voz questionadora presente no poema? Parece-nos que seu discurso é mobilizado por aquela estratégia que, desde o mundo grego antigo, torna os sujeitos questionadores e contestadores da produção alienada/alienante de seus destinos. Tratamos aqui da estratégia discursiva da parresía, vista além de suas peculiaridades oratórias e religiosas, mais propriamente no campo de posicionamentos libertários de busca constante de princípios éticos ${ }^{3}$ pragmaticamente isonômicos e até

${ }^{3}$ Seguimos as reflexões idealistas/idealizantes de Immanuel Kant (2009) sobre ética e moral em dialogia com tratamentos contemporâneos sobre o tema, como os estudos de Agamben (1993), Souza (2016) e, sobretudo, com o aporte reflexivo de Michel Foucault (2011; 2010; 2006). 
mesmo revolucionários perante dispositivos de ordem arbitrárias e coercitivas. Esse procedimento ousado de questionamento e de enfrentamento supõe exposição corajosa que pode inclusive colocar o sujeito em sério risco de exclusão do contexto maior, que é o socius tradicionalmente estabelecido. Como mencionamos anteriormente, seguimos o fenômeno da parresía, como fala esclarecedora, educativa e, sobretudo, reconstrutora de determinado tecido social, na perspectiva foucaultiana. Vejamos um dos desdobramentos de sua reflexão:

Pois bem, creio que a parresía é de certo modo uma espécie de palavra mais alta, mais alta que o estatuto de cidadão, diferente do exercício puro e simples do poder. É uma palavra que exercerá o poder no âmbito da cidade, mas, é claro, em condições não tirânicas, quer dizer, declarando a liberdade das outras palavras, a liberdade dos que também querem ocupar a primeira fileira nessa espécie de jogo agonístico característico da vida política, na Grécia e sobretudo em Atenas (Foucault, 2010, p. 97-98).

A parresía trata, então, da exposição franca, corajosa e, por vezes, iconoclasta de verdades necessárias e decisivas que não estavam visíveis para a maioria da comunidade disposta em contexto democrático. Seu expositor usa de uma estratégia discursiva e politizada que lhe pode proporcionar certo lugar oracular ou confessional ou político com a interlocução que é capaz de construir. Esse espaço social é construído na agônica história que perfaz o heterogêneo tecido social, mobilizado por constantes confrontos de interesses. Sendo assim, o sujeito, que usa a estratégia político-discursiva da parresía, encontra-se em iminente risco político de ter suas verdades críticas aceitas ou não aceitas no contexto de dialogia historicamente assimétrica, no qual haveria uma fonte da verdade crítica e relativizada e uma assembleia de interlocutores que ainda não conseguira vislumbrar tal verdade. Uma das consequências de tal situação de enfretamento e de negociações é o risco da não aceitação da novidade proposta, ou de princípios éticos encobertos que são desvelados, e a exclusão psicofísica do corajoso usuário da parresía.

Coragem, ousadia e certa postura pedagógica fazem parte do sujeito que toma a palavra desveladora, crítica e revolucionária na tentativa de dar consistência e visibilidade a outras possibilidades existenciais. Essa é a atmosfera do poema Mula de Deus, bem como da narrativa central, modelada no gênero de prosa, de Vittorio. E, sobretudo, é a tal ambiência do campo complexo das relações semântico-pragmáticas dispostas pelos 
biografemas que evocam disposições comportamentais da vida da própria Hilda Hilst, tanto no campo da construção de seu projeto estético quanto nas suas relações com os grupos humanos e não humanos com os quais manteve sempre um convívio intenso, direto e franco. Sintomático é, nesse quadro, sua precoce preocupação com seu envelhecimento pessoal, com a perspectiva de sua própria morte e com os variados sentidos que isso poderia implicar a posteridade que leria suas obras literárias e seria influenciada por elas.

\section{A morte deslocada pela postura ecológica}

Mula de Deus, como mencionamos, também é um poema sobre a velhice e a morte iminente, bem como sobre as exigências e consequências sociais e culturais desses fenômenos para o sujeito ainda vivente. De acordo com valores hegemônicos da cultura ocidental, somos educados a encarar aquela "que não pode ser enfrentada" de modo civilizado. Ou seja, deveríamos saber enfrentar a morte de modo digno e elegante. Nossa resposta a esse fenômeno repleto de mistérios deveria ser feita na plena aceitação, no silêncio respeitoso, na consciência apaziguada, no fluxo desejoso estancado e, por fim, na individualidade redimida pela instância metafísica tradicional e arbitrariamente oficial.

Nesse quadro sobre a finitude, temos uma já clássica visão que é diferenciada para o universo humano e para o animal, feita por Arthur Schopenhauer:

$\mathrm{O}$ animal vive sem conhecimento verdadeiro da morte: por isso o indivíduo animal goza imediatamente de todo o caráter imperecível da espécie, na medida em que só se conhece como infinito. Com a razão apareceu, necessariamente entre os homens, a certeza assustadora da morte. Mas, como na natureza, a todo mal sempre é dado um remédio ou, ao menos, uma compensação, então a mesma reflexão, que originou o conhecimento da morte, ajuda também nas concepções metafísicas consoladoras, das quais o animal não necessita, nem é capaz. Sobretudo para esse fim estão orientadas todas as religiões e sistemas filosóficos, que são, portanto, antes de tudo, o antídoto da certeza da morte, produzido pela razão reflexionante a partir de meios próprios. O grau, todavia, em que se atinge esse fim é bastante diverso, e com certeza uma religião ou filosofia capacitará o homem, muito mais do que outra, a encarar com um olhar tranquilo a face da morte" (Schopenhauer, 2000, p. 59-60). 
Nossa razão reflexionante, quando conformada por certo modo dialético, seria capaz de nos separar do mundo animal não pensante. Essa separação entre homo sapiens sapiens e demais seres vivos é o quadro que nossos conhecimentos sistemáticos, e ainda provisórios, são capazes de nos propiciar por agora. Porém, o fenômeno da finitude parece exigir mais que princípios éticos hegemônicos e comportamentos morais de aceitação educada, que nos são sistematicamente ensinados e exigidos.

Como seguimos na citação anterior, dois clássicos horizontes são colocados diante dos mistérios ainda insondáveis da morte. Temos o horizonte das metafísicas religiosas e o da filosofia. Se o primeiro trabalha com nossas sensações, sentimentos e certo conhecimento intuitivo, o segundo nos molda valores e saberes relativamente racionalizados pelas culturas nas quais estamos insertos/incertos. No segundo horizonte, a dimensão cultural é projetada por ambiências culturais, sociais e políticas que moldam a perspectiva do sujeito quanto a seu comportamento diante da finitude inexorável que é a morte.

Nesse segundo quadro, de se questionar a tradição quanto a um fenômeno crônico da evolução do ser vivo, é que encontramos a subjetividade poética de Hilda Hilst, que se coloca como voz questionadora sobre as engenharias que seu locus é capaz de lhe oferecer. Ela não aceita, pois, de modo acrítico os moldes comportamentais que lhe cobram, procurando com toda a gama de saberes, conhecimentos e intuições compreender o contexto final no qual se encontra.

De certa forma, o eu lírico, na alegoria da mula envelhecida e supostamente já disfuncional, permite-se assumir a postura que contesta de modo assistemático o que lhe cabe nessa fase e como deve se portar diante do fato. Sua posição é, pois, diferenciada daquela posição tranquilizada, como podemos acompanhar no poema:

VII

Que eu morra junto ao rio.

O caudaloso frescor das águas claras

Sobre o pelo e as chagas.

Que eu morra olhando os céus:

Mula que sou, esse impossível

Posso pedir a Deus. E entendendo nada

Como os homens da Terra.

Como as mulas de Deus. 
VIII

Palha

Trapos

Uma só vez o musgo das fontes

O indizível casqueando o nada.

Essa sou eu.

Poeta e mula.

(Aunque pueda parecer

Que del poeta es locura) (Hilst, 2006, p. 127).

Uma alma relativamente apaziguada poderia emergir do quadro densamente poético. No entanto, tal poeticidade rebelde é um forte marcador dessa subjetividade que se contorce de modo resistente perante o inevitável que não poderia ser questionado e reinventado. A subjetivação poética possui densas relações com o mundo humano e com o mundo natural de complexas redes ecológicas. Sua constituição psicossocial e cosmovisão são, por consequência, rizomáticos, no sentido de se colocar de modo ativo perante a realidade múltipla que lhe é imposta de modo monológico.

A preocupação quanto à preparação para a morte, tradicionalmente imposta pela nossa cultura, também é refletida por Michel Foucault, quando pensa sobre os cuidados que haveríamos de ter para conosco, segundo quadros normativos de nossa cultura hegemônica. Vejamos um dos desdobramentos de suas reflexões:

A meditação sobre a morte é, em sua forma geral, totalmente isomorfa à presunção, à premeditação dos males de que lhes falava há pouco, simplesmente por esta primeira razão: a morte não é apenas um acontecimento possível, é um acontecimento necessário. Não é apenas um acontecimento com alguma gravidade: tem para o homem a gravidade absoluta. E enfim a morte pode ocorrer, bem sabemos, a qualquer momento. Portanto, se quisermos, é realmente para este acontecimento como infortúnio por excelência que devemos nos preparar pela meléte thanátou, que constituirá um exercício privilegiado, aquele no qual ou pelo qual precisamente faremos culminar a premeditação dos males. Entretanto, há algo de específico na meditação sobre a morte, e é isto que gostaria de expor. (Foucault, 2006, p. 579-580). 
Michel Foucault continua aqui a tentar compreender como segmentos tradicionais de nossa cultura ocidental criam manuais de comportamento supostamente cordato perante a situação da morte. O comportamento em questão seria responsável pela manutenção de certa ordem social, mesmo que tal ordem não seja de fato disseminada de modo isonômico por todo o conjunto social. O alvo maior do sujeito moribundo seria o de morrer em silêncio, afetando o mínimo possível o equilíbrio de sua rede interpessoal. A premeditação dos males, nesse ato de morrer de modo apaziguado, diz respeito mais aos princípios de equilíbrio do socius fortemente estratificado que aos princípios do foro íntimo da pessoa. Meditar sobre a morte, nessa perspectiva dos cuidados de si, tanto no mundo antigo grego quanto no contemporâneo, faz com que Foucault reflita sobre mais um dos mecanismos de controle alienantes que atuam sobre nossas vontades pessoais e sobre outras possibilidades de vivenciarmos o fenômeno da morte.

Diante disso, notamos que a mula, nesse poema de Hilda Hilst, está com o seu pelo marcado pelas chagas causadas por sua teimosia. Essa não aceitação é demonstrada pela postura efetivada pela mula em querer compreender os mecanismos que a fizeram chegar a tal estado de sofrimento - condição essa, em alguns momentos, encoberta pela aceitação cínica da condição a que chega.

Sua posição de calmaria é hibridizada pela coragem e ousadia, efetivação da parresía cínica, que lhe toma a consciência em fluxo ininterrupto. Sua coragem é envolvida na constatação de que a linguagem dos poetas pode aproximar-se inclusive da a-significação, comumente tida como postura de subjetividades supostamente enlouquecidas, que são capazes de colocar as situações éticas e morais de suas vivências e convivências sob o escrutínio feito por valores diferenciados da ordem comum.

Nesse ponto, pensamos na influência, consciente ou não, que esse poema e a narrativa central na qual ele está inserido, recebem do pensamento ecocrítico. ${ }^{4}$ Mais que daquela já convencional alegoria da

\footnotetext{
${ }^{4}$ Sobre o contexto do campo de estudos da ecocrítica, segundo Greg Garrard, temos que: “À medida que os ecocríticos procuram oferecer um discurso verdadeiramente transformador, que nos permita analisar e criticar o mundo em que vivemos, dá-se cada vez mais atenção à ampla gama de processos e produtos culturais nos quais e por meio dos quais ocorrem as complexas negociações entre a natureza e a cultura. Aliás, a definição mais ampla do objeto da ecocrítica é a de estudo da relação entre o humano e o não-humano, ao longo de toda a história cultural humana e acarretando uma análise crítica do próprio termo "humano" (Garrard, 2006, p. 16). Dessa forma funciona, como tentamos evidenciar, o tratamento ecológico dado a vários tropos da obra de Hilda Hilst.
} 
mula metafísica, ${ }^{5}$ essa narrativa complexa também está a tratar de marcadores subjetivos relacionados com certa referencialidade de matiz ecológica. É notório o uso que Hilda Hilst faz de suas variadas experiências pessoais em sua Casa do Sol, seu sítio nos arredores da cidade de Campinas, no estado de São Paulo.

Nesse espaço densamente ecológico, a escritora demonstrou forte laços com o mundo animal, com o vegetal e com o mineral. Apesar de suas profundas relações com o espaço urbano, como o da capital paulistana e outras metrópoles mundiais, Hilda afasta-se desse universo para fazer uma imersão radical no espaço interiorano e ecológico. Nesse lugar minuciosamente construído para respeitar e conviver com o meio ambiente complexo, é possível vê-la cuidando de mais de uma centena de cães, de várias espécies de aves, de um rol de plantas, como sua real, mesmo que também simbólica, figueira no centro do jardim do sítio, e até mesmo dos elementos mais básicos do mundo mineral, como a terra, a água, o ar e o fogo.

Em Estar sendo: ter sido, e em outras tantas de suas obras, podemos elencar uma miríade de seres desses outros campos considerados de modo tradicional como não humanos. Tal ênfase nessas representações e expressões de outros seres bióticos e abióticos pode, inclusive, redimensionar a ideia que a escritora possuía do que seria realmente a dimensão particularmente humana.

Com essa perspectiva ecocrítica, aventamos a hipótese de que a subjetividade lírica da escritora propõe um argumento de que a dissolução final da pessoa humana possa ser atenuada pela crença de que certo animismo seria capaz de nos redimir e de nos transformar em relação a uma suposta ineficiência em aceitarmos as condições dos rituais que fazemos aos fenômenos do envelhecimento e de morte que nos são exigidos. Vejamos, por fim, um exemplo de como tal amplitude ecocrítica ocorre no poema em estudo:

IV

Um dia fui o asno de Apuléius.

Depois fui Lucius, Lucas, fui Roxana.

\footnotetext{
${ }^{5}$ Um exemplo dessa perspectiva predominantemente metafísica do tropo Equus Mulus pode ser acompanhado em Rubens Cunha (2010).
} 
Fui mãe e meretriz e na Betânia

Toquei o intocado e vi Jeshua

(Ele tocou-me o ombro aquele Jeshua pálido).

Um tempo fui ninguém: sussuro, hálito.

Alguém passou, diziam? Ninguém, ninguém.

Agora sou escombros de um alguém.

Só caminhada e estio. Carrego fardos

Aves, patos, esses que vão morrer.

Iguais a mim também (Hilst, 2006, p. 125).

Na perspectiva oferecida pela ecocrítica, o nivelamento de importância entre o ser humano e os demais seres quebra a hierarquia disposta pelos mecanismos culturais conservadores de nossa sociedade. Criador e criaturas são colocados no mesmo nível de importância ontológica e filogenética. A igualdade entre o eu lírico, que ousa questionar seu suposto criador sobre sua fragilidade humana e sua necessidade de compreender os porquês de tais fragilidades, e, por exemplo, aves, patos e uma mula já imprestável, proporciona a percepção de um universo existencial complexo, diverso e heterogêneo no qual se modifica a centralidade da consciência presa em sua dimensão individual, de cunho antropocêntrico.

A mula de Deus seria, então, formada até mesmo provisoriamente por realidades heterogêneas mais complexas que aquelas da individualidade centrada em uma suposta essência humana exclusiva e excludente. Novas sínteses, como as de inclusão disjuntivas, são colocadas nos jogos dos processos de subjetivações possíveis, tanto no campo da ecologia mental, no da ecologia social, quanto no estratégico campo da ecologia ambiental. Essa última é nitidamente marcada pelo projeto existencial que Hilda Hilst teve ao construir sua Casa do Sol, atualmente denominada por Instituto Hilda Hilst. ${ }^{6}$

\footnotetext{
${ }^{6}$ Para marcar o caráter de ativismo cultural, político e ecocrítico da obra de Hilda Hilst, indicamos uma visita à homepage da Casa do Sol, hoje denominada de Instituto Hilda Hilst. Instituição brasileira de singular fomento e divulgação do acerto da escritora, bem como lugar que funciona como oficina de acolhimento, produção e valorização de trabalhos artísticos variados. Disponível em: <http://www.hildahilst.com.br >. Acesso em: 20 set. 2016. Mais dados sobre a biodata da autora e seu projeto estético podem ser acompanhados em panorama abrangente oferecido nos Cadernos de Literatura Brasileira, n. 99, publicado pelo Instituto Moreira Salles.
} 


\section{O cinismo dialético na hibridização poesia-prosa e nas subjetivações transversais}

A narrativa em questão, montada pelo dialogismo tenso entre gêneros discursivos de prosa e poesia, expressa também certo procedimento discursivo cínico, ${ }^{7}$ advindo da estratégia do uso da parresía em sua tentativa de resgate de condições éticas e morais isonômicas, por mais variadas que sejam, nas coexistências intersubjetivas. No plano estético, forma e conteúdo são vistos em sua natureza de amálgama ontológica, no sentido de que uma realidade está contida na outra. Assim, aqui, seguimos uma textualidade que se desborda e se contorce como as temáticas que envolvem o eu lírico do poema Mula de Deus e na narrativa de/sobre o protagonista Vittorio.

Relembremo-nos, por agora, do contexto vivencial de Vittorio, aquela subjetividade que também perfaz a mula de Deus e os biografemas de Hilda Hilst.

Ao contrário de agir conforme a tradição costuma planejar e exigir que a pessoa idosa haja, Vittorio insiste, em sua textualização de narradorprotagonista, em demonstrar seus fluxos e intensidades pertinentes ao princípio do prazer. Tenta agarrar-se a ações e situações que conhece e que lhe deem certo controle sobre o mundo a seu redor, sobre si mesmo e sobre as forças que asseguram a vida de acordo com o que também seria sua vontade de vida.

De certa forma, seu comportamento proativo em relação à continuidade da condição de sujeito relativamente autônomo e independente é um elemento que marcará sua velhice de forma singular. Como acompanhamos, por exemplo, na situação em que Vittorio é obrigado a usar uma bengala para lhe amparar as insuficiências físicas. Ele adquire uma bengala que simboliza um poder diferenciador, pois o cabo de tal bengala tem a cabeça de um tigre, animal dos mais capazes e ferozes da natureza. Assim, um instrumento simbólico de insuficiências físicas assume também o papel da estratégia protetiva mais ampla que o usual.

Vittorio seria um sujeito semelhante a um velho tigre que ainda luta por manter sua potência de luta? Mesmo sentindo os passos da morte próximo de si, saberia inventar jogos e negociações para protelar ou controlar a situação adversa? De início, parece que sim, pois o vemos

\footnotetext{
${ }^{7}$ Para maiores desdobramentos sobre a dimensão filosófica da parresía cínica do mundo antigo grego e de seus sentidos contemporâneos, por vezes contraditórios, além da obra indicada de Michel Foucault, também acompanhamos Mazella (2007), Laursen (2009), Dudley (2016) e Grane (2016).
} 
produzindo várias situações típicas de sujeitos produtores de capitais variados, tais como: planejar seduzir sexualmente as jovenzinhas a seu redor; manter o domínio de seu núcleo familiar; montar e consolidar as narrativas de amigos e de pessoas que lhe passaram pela vida; imaginar e encenar talvez o teatro que envolve seu casamento com Hermínia, bem como a suposta triangulação amorosa na qual obriga a ex-mulher a ficar; enfim, uma série de atividades é mostrada, distanciando esea pessoa idosa daquele estereotipo de velhice fraca e desvalida.

A vontade de vida e o erotismo fundador de universos existenciais, tidos como força vital que mantém o corpo em movimento de construção constante, são ainda sintomas de presença vívida e exigentes de sua participação. E isso é talvez o que cria uma constante de atritos entre esse protagonista e as pessoas que estão a sua volta. Mesmo tido como estranho, Vittorio é relativamente tolerado por sua rede de vivência interpessoal. Habitualmente, a outridade normalizadora e excludente, apesar de enquadrá-lo como um estranho suspeito, tem planejamentos comportamentais para ele. No entanto, em certas circunstâncias, aquelas nas quais os desejos do velho são expostos de modo veemente, há também presença de respostas contestatórias e de franco e cínico contra-ataque. Como se para neutralizar as ditas de que à pessoa idosa já não cabe tanta vontade de vida e que elas precisam aceitar de modo educado e apaziguado o traçado ético e moral tradicional e o desligamento final de suas funções psicossociais.

Matias, o irmão de 45 anos, e Júnior, o filho adolescente, vez em quando são capazes de pronunciar sintéticas opiniões e juízos negativos ao que seriam os excessos comportamentais de Vittorio. Não se alongam em tais posicionamentos, porém deixam claro que o parente envelhecido, por vezes casmurro e grotesco, costuma ultrapassar os limites das liberdades criativas que lhe poderiam ser permitidas. ${ }^{8}$ Mesmo que não tão quantitativamente fortes como se segue no caso da senhora $D$., personagem intertextualizada nessa narrativa em questão, aqui o aspecto qualitativo de tais julgamentos negativos parece até mesmo intensificar as debilidades corporais e mentais de Vittorio. Sua sensação a respeito de uma possível e breve morte consolidase; e, aí sim, seu fluxo desejoso de erotismo sexual ou erotismo para efetivar concretamente quaisquer outras atividades que possam mantê-lo vivo parece

\footnotetext{
${ }^{8}$ Simone de Beauvoir, no capítulo "A velhice nas sociedades históricas", em A velhice (1990), detalha os dispositivos de repressões e recalques psicossociais sofridos pela pessoa envelhecida. Tais controles tradicionais ocasionam crônicas condições de falta de autonomia e de independência para tal fase da vida.
} 
enfraquecer de modo alarmante, como acompanhamos nessas reflexões, aparentemente feitas por um fluxo de consciência:

Aí é:

Imagem sol

Imagem esfera

Monto

Agora sobre o teu dorso

Ereto

Planisfera una e vertical

Plena

Umasomúltiplamatéria.

Pensar que isso sou eu. E o morto que há em mim. O roto. $\mathrm{O}$ decomposto. Alguém lá dentro me diz que estou sendo injusto. Que há mortos muito mais putrefatos, a cara expelindo ranço e desgosto, que aquele, o Oscar: o Fingall, o O'Flahertie Wills, aquele, o Wilde, quando morreu, tudo estourou dentro dele, que o estômago explode, é o que dizem quando se está na pira, na Índia talvez, e ouve-se uma explosão a muitos passos dali. Eu e minha "intensa fisiose", como dizem os médicos, o que você come, heim um saco de ventos? Engoliste, Vittorio, o fole de pele de boio onde Éolo guardava os ventos? (Hilst, 2006, p. 82).

Ao lado de vislumbrar a condição rizomática com as demais pessoas a sua volta, Vittorio medita, mesmo que de modo enviesado, sobre sua morte, as mortes alheias e exercita-se para o momento que julga inalienável. Desta forma, poderíamos pensar que ele se entrega ao niilismo da condição de envelhecimento inativo na qual forçosamente deveria se encontrar. Os dados comportamentais e suas consequências indicam que ele realmente está no fim da linha e sem ver quaisquer luzes consoladoras no fim do túnel, mesmo que compare a suposta gravidade de seu caso com vidas que historicamente tiveram e ainda têm uma cota de sofrimento realmente intensa.

Junto a esse quadro de ações, reações e situações de sofrimento crônico, percebemos que o fragmento citado misturou gêneros narrativos, ${ }^{9}$ prosa e poesia. Essa situação discursiva existe em uma daquelas espécies de anacolutos que produzem uma carga semântica polivalente, própria do

\footnotetext{
${ }^{9}$ Para a temática da hibridização dos gêneros literários, bem como seu uso como dispositivos de resistência a padrões conservadores e arbitrários de produção discursiva, acompanhamos as reflexões de Jean-Marie Shaeffer (1986).
} 
texto literário, que mais que oferecer respostas para grandes perguntas, tenta mobilizar seu corpo para tornar seus potenciais leitores em sujeitos capazes de também questionar e montar suas hipóteses semânticas no jogo literário, cultural e político das enunciações dispostas em constantes e estratégicos fluxos. Nesse jogo, acompanhamos um dos mais intensos protagonistas de nossa literatura em suas tentativas de compreensão de seu estado de velhice e de sua vontade em continuar a criar e a manter condições de sobrevivência e de coexistência dialógica, mesmo que isso exija registros de inversão de sentidos e de várias denegações que lhes protegeriam a capacidade de ação e intervenção tanto em seu foro íntimo quanto em sua rede interpessoal.

Envoltos pela moldura dessa narrativa, que é a última de Hilda Hilst, como já mencionamos, ficamos tentados a fazer algumas perguntas, nesse processo de leitura teórico-analítica a qual tentamos dar corpo. De fato, pessoas idosas possuem dispositivos autoprotetivos eficientes, do ponto de vista ético e moral tradicionais, nesse contexto psicossocial de evolução humana? Velhice e morte são fenômenos naturais e socioculturais que permitem a produção de identidades transversais ${ }^{10}$ capazes de resistir a situações de constrangimentos, vulnerabilidade e exclusões das mais diversas naturezas?

Essa transversalidade, na possibilidade de resistência, é condensada no poema Mula de Deus, com fina perspectiva estratégica da parresía cínica, que é usada por Hilda Hilst, nessa complexa e multiforme narrativa. A voz da subjetividade em curso, e a postura nada educada, considerando a tradição, perante os sofrimentos psicossociais acarretados coercitivamente pelas convenções sociais sobre a velhice e a iminência da morte, coloca-se no campo de algo semelhante ao que seria a voz perversa e cínica da aldeia. É uma voz que traz novas perspectivas dos fenômenos que submetem o ser humano, bem como os demais seres vivos, a espaços vivenciais de medo, de contrição e de subserviência perante dispositivos de controle do fluxo dos potenciais e múltiplos campos desejosos do sujeito. Nesse ponto, voltamos à terceira estrofe do poema, que citamos como uma das epígrafes no início desse estudo:

${ }^{10}$ Sobre o conceito de identidade transversal, conformada e percebida além da tradição positivista do fenômeno nucleado e individualizado, seguimos os estudos ecocríticos de Gregory Bateson (1977; 1987), e os de Félix Guattari (1990). 
III

Escrituras de pena (diria mais, de pelos)

De infinita tristura, encerrada em si mesma.

Quem há de ouvir umas canções de mula?

Até das pedras lhes ouço a desventura.

Até dos porcos lhes ouço o cantochão

E por que não de ti, poeta-mula?

E ornejos de outras mulas se juntaram aos meus.

Escoiceando os ares, espumando de gozo

Assustando mercado e mercadores

Alegrou-se de mim o coração (Hilst, 2006, p. 124).

Essa volta ao intratexto poemático faz-se necessária para marcarmos a posição cínica que o sujeito (mula/subjetividade) ecológico tenta produzir para fazer frente, de modo ativo e cínico, à dureza das formações discursivas que lhe obliteram o fluxo desejoso. Nota-se certa conclamação à interlocução para que lhe aprove as ações corajosas de resistência a princípios de ordem e de justiça não isonômicos. Outras mulas - nós leitores? -, escoicearão os ares, espumando de gozo e assustando mercado e mercadores?

A triste acomodação aos bônus exigidos pela metafísica consoladora pode, portanto, dar lugar a um coração capaz de se alegrar cinicamente mesmo diante de situações aparentemente irremediáveis. Essas situações, formadas pelos fenômenos do envelhecimento, da velhice instalada e da morte, talvez já não sejam mais capazes de impedir a consecução do projeto de vida pessoal e coletivo que é contemplado pelo princípio das ecologias de fato dialógicas e transversais.

\section{Considerações finais}

O poema Mula de Deus tenciona a condição humana entre o plano da submissão perante forças desconhecidas, certa metafísica positiva, e o plano da resistência via parresía cínica. A "nadificação" estratégica movida pelo eu lírico do poema final, e também pelo protagonista Vittorio, que ocupa a narrativa central dessa obra, funciona como ação avaliadora e contestadora que aponta a capacidade de resistência que Hilda Hilst expressa de forma franca e corajosa, nessa sua última obra publicada em vida. Há, pois, um comportamento psicossocial que cobra 
posturas éticas e morais relativizadas em nossa sociedade, estruturadas por valores, crenças e atitudes diversas, de acordo com as variadas engenharias políticas.

A "demasiada coitadez" que paira sobre a superfície textual das histórias do velho Vittorio e da mula moribunda, que também enlouquecem diante das disfuncionalidades que a velhice e a iminência da morte lhes trazem, é condensada na voz do eu lírico do poema que fecha essa revolucionária narrativa. Revolucionária tanto nos aspectos formais quanto na temática franca e cínica. Velhice e morte, temas usualmente silenciados em nossa cultura tradicional, que valoriza enormemente vidas jovens em fase de franca produtividade de capitais variados e supervalorizados, são vivenciados e expressos através da perspectiva que resiste às convenções e preconceitos culturais.

A parresía cínica funciona aqui como aquela voz que alerta, de modo socioestético e também propedêutico, sobre as cartografias de situação e ações que permeiam o cotidiano, sem que se tenha, por vezes, consciência dos dispositivos sociais e políticos que produzem, reproduzem e dinamizam tais contextos.

Estar sendo: ter sido, com sua mise en abyme obtida pelo/com o poema Mula de Deus, faz parte, portanto, daqueles textos de resistências, dos quais Roland Barthes, por exemplo, incita-nos a conhecer e vivenciar. Hilda Hilst, no contexto do prazer do texto, parece também conclamar os leitores a fazer parte desse exercício de textualização de prazeres e resistências intrínsecos a qualquer tipo de vida no plano da natureza agônica, na qual o texto literário também é coproduzido. Nessa atmosfera, encerramos este artigo com a ideia do que seria esse prazer do texto, na perspectiva barthesiana:

O prazer do texto não é forçosamente do tipo triunfante, heroico, musculoso. Não tem necessidade de se arquear. Meu prazer pode muito bem assumir a forma de uma deriva. A deriva advém toda vez que eu não respeito o todo e que, à força de parecer arrastado aqui e ali ao sabor das ilusões, seduções e intimidações da linguagem, qual uma rolha sobre as ondas, permaneço imóvel, girando em torno da fruição intratável que me liga ao texto (ao mundo) (Barthes, 1987, p. 26-27).

Talvez, na conjuntura desse prazer do texto, Hilda Hilst ofereça ao leitor contemporâneo os difíceis gozos socioestéticos da escrita literária 
complexa e amplamente polifônica. Soma-se a isso a expressão de um quadro humano disposto na dimensão da vulnerabilidade diante de um socius ainda adverso à ética e moral proteiformes de sociedades equânimes que sejam capazes de construir o bem-estar coletivo, que se refere, em nosso recorte, ao envelhecimento e à morte, bem como ao corolário que disso surge.

Tal vulnerabilidade, de acordo com algumas estratégias observadas em A mula de Deus, aponta possibilidades de negociações psicossociais equilibradas, através também da prática ecológica, da filosofia enraizada no real sensível e da desconstrução dos, por vezes, improdutivos e cruéis dispositivos de religiosidade produzidos pelas metafísicas de cunho consolador e alienante.

\section{Referências}

AGAMBEN, Giorgio (1993). A comunidade que vem. Tradução de António Guerreiro. Lisboa: Presença.

BARTHES, Roland (1987). O prazer do texto. Tradução de J. Guinsburg. São Paulo: Perspectiva.

BARTHES, Roland (1994). Roland Barthes par Roland Barthes. Tradução de Richard Howard. Los Angeles/Berkeley: University of California.

BATESON, Gregory (1977). Vers une écologie de l'esprit. Traduit de l'Anglais par Perial Drisso, Laurencine Lot et Eugène Simion. Paris: Seuil, 1977.

BATESON, Gregory (1987). Steps to an ecology of mind. Collected essays in anthropology, psychiatry, evolution, and epistemology. London: Jason Aronson.

BEAUVOIR, Simone de (1980). A velhice. Tradução de Maria Helena Franco Monteiro. Rio de Janeiro: Nova Fronteira.

BOURDIEU, Pierre (1996). Razões práticas: sobre a teoria da ação. Tradução de Mariza Corrêa. Campinas: Papirus.

CADERNOS DE LITERATURA BRASILEIRA (1999). Hilda Hilst. São Paulo: Instituto Moreira Salles.

CUNHA, Rubens (2010). Mula de Deus: o impossível pedido. Anuário de Literatura, Florianópolis, v. 15, n. 1, p. 208-218.

DUDLEY, Donald R (2016). A history of cynicism: from Diogenes to the $6^{\text {th }}$ Century A. D. London: Methuen \& Co. LTD. 
FOUCAULT, Michel (2006). A hermenêutica do sujeito. Curso dado no Collège de France (1981-1982). Tradução de Márcio Alves da Fonseca e Salma Tannus Muchail. São Paulo: Martins Fontes.

FOUCAULT, Michel (2010). O governo de si e dos outros. Curso dado no Collège de France (1982-1983). Tradução de Eduardo Brandão. São Paulo: Editora WMF Martins Fontes.

FOUCAULT, Michel (2011). A coragem da verdade: o governo de si e dos outros II. Curso no Collège de France (1983-1984). Tradução de Eduardo Brandão. São Paulo: WMF/Martins Fontes.

GARRARD, Greg (2006). Ecocrítica. Tradução de Vera Ribeiro. Brasília: Editora da Universidade de Brasília.

GENETTE, Gérard et al (1986). Théorie des genres. Paris: Seuil.

GRANE, Gregory R. (Ed.) (2016). Diogenes Laertius: lives of eminent philosophers. [S.1.]: Perseus Digital Library. Disponível em: <http://www.perseus.tufts.edu/hopper/text?doc=D.\%20L.>. Acesso em: 10 jun. 2016.

GUATTARI, Félix (1990). As três ecologias. Tradução de Maria Cristina F. Bittencourt. Campinas: Papirus.

HILST, Hilda (2006). Estar sendo: ter sido. 2. ed. São Paulo: Globo.

INSTITUTO CASA DO SOL (2016). Hilda Hilst. Disponível em: <http:/ /www.hildahilst.com.br>. Acesso em: 20 set. 2016.

KANT, Immanuel (2009). Fundamentação da metafísica dos costumes. Tradução, introdução e notas de Guido de Almeida. São Paulo: Discurso; Barcarola.

LAURSEN, John Christian (2009). Cynism then and now. Iris, Firenze, v. I, n. 2, p. 469-482, Oct.

MAZELLA, David (2007). The making of modern cynicism. Charlottesville, VA: University of Virginia Press.

SCHAEFFER, Jean-Marie (1986). Du texte au genre. In: GENETTE, Gérard et al. Théorie des genres. Paris: Seuil, p. 179-205

SCHOPENHAUER, Arthur (2000). Metafísica do amor. Metafísica da Morte. Tradução de Jair Barboza. São Paulo: Martins Fontes.

SOUZA, Ricardo Timm de (2016). Ética como fundamento: pequeno tratado de ética radical. Caxias do Sul: Educs, v. 2 
Recebido em 20 de setembro de 2016.

Aprovado em 15 de fevereiro de 2017.

\section{resumo/abstract/resumen}

\section{Filosofia cínica contemporânea e dispositivos éticos de resistência em Mula de Deus, de Hilda Hilst}

Jorge Alves Santana

"Quem há de ouvir umas canções de mula?" é uma das perguntas feitas pelo eu lírico do poema Mula de Deus, que finaliza a narrativa Estar sendo: ter sido (2006), de Hilda Hilst. Último livro da produção literária da escritora, esta obra trata de modo filosófico de temas como: a instalação da velhice, a finitude humana e as tensões cínicas entre a pragmática animista da vida humana, entre outros, frente às supostas consolações e redenções produzidas pela metafísica tradicional. Este estudo focará predominantemente essas tensões, no poema referido, entre o animismo ecocrítico, animado pela corrente da Filosofia Cínica através do conceito de parresía, e certo viés religioso conservador. Contexto temático que também é refletido na modalidade de gênero textual híbrido, poesia e prosa, na qual a escritora expressa um dos possíveis balanços de sua estética.

Palavras-Chave: Mula de Deus/Estar sendo: ter sido, ética cínica, parresía, Hilda Hilst.

\section{Contemporary cynical philosophy and ethical devices of resistance in the poem Mula de Deus by Hilda Hilst}

Jorge Alves Santana

"Who will listen to songs of a mule?" is one of the questions posed by the narrator in the poem Mula de Deus that finishes the narrative Estar sendo: ter sido (2006), by Hilda Hilst. As the author's last book this volume uses a philosophical in order to approach themes such as: ageing, human finiteness, and the cynical tensions between the animist pragmatic, among other, comparing these to the supposed solaces and redemptions produced by traditional metaphysics. This study focuses mainly on the tensions, in the poem, between the ecocritical animism, encouraged by the a current of Cynical philosophy through the notion of parrhesia, and a certain conservative religious bias. This thematic context is also reflected in the hybrid literary genre, which oscillates between poetry and prose, through which the writer expresses one of the possible balances of her aesthetics. 
Keywords: Mula de Deus/Estar sendo: ter sido, cynical ethics, parrhesia, Hilda Hilst.

\section{Filosofía cínica contemporánea y dispositivos éticos de resistencia en Mula de Deus, de Hilda Hilst}

Jorge Alves Santana

"¿Quién ha de oír unas canciones de mula?" es una de las preguntas formuladas por el yo lírico del poema Mula de Deus, que termina la narración Estar sendo: ter sido (2006), de Hilda Hilst. Último libro de la obra literaria de la escritora, este trabajo trata de una manera filosófica temas tales como la instalación de la vejez, la finitud humana y las tensiones cínicas entre la pragmática animista de la vida humana, entre otros, en contra de los presuntos consuelos y redenciones producidos por la metafísica tradicional. Este estudio se centrará predominantemente en las tensiones, en el poema referido, entre el animismo ecocrítico animado por la filosofía cínica a través del concepto de parresía, y algunos prejuicios religiosos conservadores. Contexto temático que también se refleja en la forma de género textual híbrido, la poesía y la prosa, en que la escritora expresa uno de los posibles balances de su estética.

Palabras clave: Hilda Hilst, Mula de Deus/Estar sendo: ter sido, ética cínica, parresía, Hilda Hilst. 